\title{
EL IEPON EN EL LÉXICO RELIGIOSO GRIEGO DESDE EL PERIODO HOMÉRICO HASTA EL PERIODO ROMANO
}

\author{
Panagiota Papadopoulou \\ Universidad de Granada. España \\ Centro de Estudios Bizantinos, Neogriegos y Chipriotas. España
}

Resumen: En la larga historia de la realidad griega, la religiosidad sufrió cambios sustanciales en sus planteamientos y creencias, un hecho que también implicó la necesidad de adaptaciones lingüísticas para expresar nuevos conceptos y requisitos de culto. Nombres monolécticos o perífrasis influenciados por la tradición filosófica griega, como resultado de su uso en toda la historia de las letras griegas, aparecen hasta hoy sin perder su concepto religioso. El término sustantivado ífóv es una de las denominaciones del lugar más sagrado e importante del templo cristiano, del presbiterio, cuya presencia comienza en el siglo VIII BC y continúa incesante hasta la actualidad.

Palabras claves: Fe - religión - culto - Grecia - adaptación lingüística.

\section{THE IEPON IN THE GREEK RELIGIOUS LEXICON SINCE THE HOMERIC AGE TO THE ROMAN PERIOD}

\begin{abstract}
In the long history of Greek reality, religiosity underwent substantial changes in their approaches and beliefs, a fact that also involved the need for linguistic adaptations in order to express new concepts and requirements of worship. Monolectic names or periphrasis influenced by Greek philosophical tradition as a result of its use throughout the history of the Greek letters appear until today

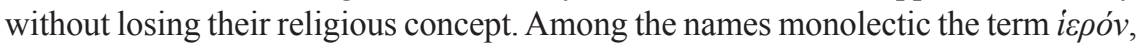
whose presence begins in the VIII BC century and continues to the present.
\end{abstract}

Keywords: Faith - religion - worship - Greece - linguistic adaptation

Recibido: 20-07-2019 - Aceptado: 31.03.2020

Correspondencia: Panagiota Papadopoulou

Email: papadopoulou@ugr.es

Universidad de Granada

Centro de Estudios Bizantinos, Neogriegos y Chipriotas

C/Gran Vía 9-2A. 18001 Granada. España 


\section{Introducción}

T a tendencia del hombre a expresar su religiosidad y a rendir culto, respeto y reconocimiento a la omnipotencia

de la divinidad, lo empujó a definir espacios sagrados $\mathrm{y}$, a continuación, a construir templos dedicados a ella y a su culto como manifestación colectiva por medio de oraciones, cantos, rituales y sacrificios [Burkert, 1985: 117-121]. Aunque la aproximación a la divinidad es diferente para el periodo pagano y el cristiano [Kalligas, 1946: 19-24], la necesidad de suplicar, alabar y agradecer a la potencia inmaterial y espiritual es común e intensa. El templo es la primera construcción oficial y pública del hombre, surgida por la necesidad de albergar la potencia sobrenatural. Es la imagen visible de la unión del ser superior con el inferior, el símbolo universal y uno de los más evocadores [Chastoupis, 1971: 57-65]. Muchas de las denominaciones de las partes que componen un templo son comunes en todos los periodos de la historia de la religiosidad en el mundo griego, a pesar de las diferencias que presentan sus manifestaciones religiosas.

En el templo cristiano el lugar más sagrado e importante, donde se celebra el sacramento esencial del culto del rito cristiano oriental, la Sagrada Comunión, es el del presbiterio ubicado en la parte más alta del templo con el fin de distinguirse y ser visible por todos. Las distintas denominaciones, que recibe en la Iglesia Oriental Griega, se distinguen, cada una con su propio significado, y expresan su santidad y su relevancia.

Es cierto, que en los tres mil años de historia registrada del mundo griego la religión, tanto en el periodo pagano como en el Cristianismo, ha desempeñado un papel muy importante. La manera de manifestar la fe durante tantos siglos sufrió cambios, hecho que se reflejó también en la lengua y en la forma de expresión. Durante el periodo protobizantino, la terminología del paganismo fue trasladada por los Grandes Padres del s. IV d. C. a las necesidades del culto cristiano [Konidaris, 1954: 153-167]. De este modo la rica situación lingüística configurada durante milenios en el culto pagano, se modificó para ser adaptada a la nueva realidad religiosa, que ya recibió la influencia de la tradición filosófica griega. En consecuencia, desde el punto de vista lingüístico, el presbiterio cristiano se expresa, en la mayoría de los casos, con términos utilizados durante el periodo pagano, términos que se siguen utilizando tras haber sufrido un proceso de adaptación al culto cristiano. Se trata, por tanto, de nombres monolécticos o perífrasis influidas por la tradición filosófica griega como consecuencia de su empleo a lo largo de la historia de las letras griegas 


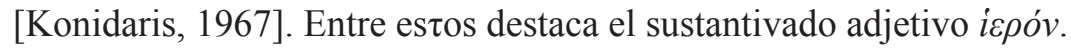

El adjetivo i $\varepsilon \rho o ́ \varsigma-\alpha ́$-óv, sagrado y su forma sustantivada en neutro -iepóv- son términosque declaran una de las características fundamentales y constantes de la religiosidad humana y es la que, según el pensamiento religioso, muestra la presencia de lo metafísico, de la divinidad, en un lugar, en un objeto o en un ser y su consagración por ella. Es el acceso de lo metafísico al mundo físico, tema tratado adecuadamente por Mircea Eliade [Eliade, 2002]. La divinidad, lo divino "aparece" en un momento concreto, en un lugar u objeto y a partir de ese momento constituye para los fieles un lugar u objeto sagrado, hasta que, por diversas causas conocidas o desconocidas, pierde su santidad. Dicha pérdida no suprime la esencia y el sentimiento de lo "sagrado", susceptible de transformación y transmisión que es lo que, exactamente, caracteriza la religiosidad griega [Garrett, 2008]. Lo "sagrado" del culto pagano se transformó para ser adaptado a la realidad cristiana y junto a su perfil dogmático tuvo que adaptarse también el lingüístico con el fin de expresar los nuevos conceptos y las exigencias de culto.

El lugar sagrado de los primeros siglos del paganismo y su forma más evolucionada, la del templo y el templo del Cristianismo, participan del mismo simbolismo. Es la morada de la presencia divina, el punto de encuentro de lo celestial y lo humano, es el simbolismo de lo sagrado. Para construir sus templos los paganos eligieron lugares indicados por señales divinas y los cristianos, tras la decadencia del paganismo, construyeron sus iglesias sobre los templos anteriores y muchas veces con los mismos

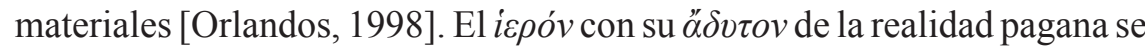
transforma en el templo con su íৎóv de la realidad cristiana, construcciones

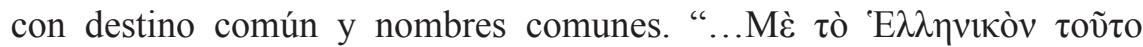

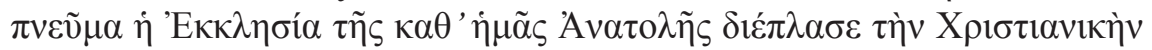

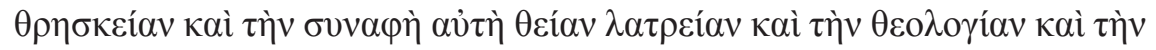

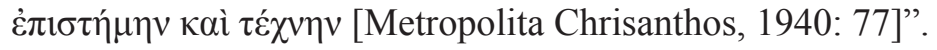

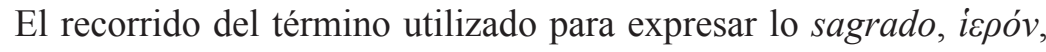
en cualquiera de sus formas aparece con claridad en la historia de las letras griegas desde el periodo homérico (1100-800 a. C.) y continúa para llegar a la Grecia moderna (1821 d. C.-actualidad), a la Grecia actual. 


\section{Periodo Homérico}

La Iliada y la Odisea de Homero son las obras en las que el término

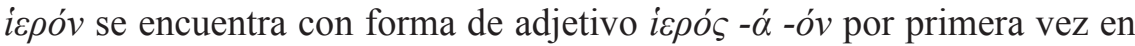
la literatura griega con el significado de sagrado para caracterizar lugares, objetos, personas o situaciones anímicas y, en general, en casos abstractos y concretos a quienes se les confiere santidad, por la presencia divina

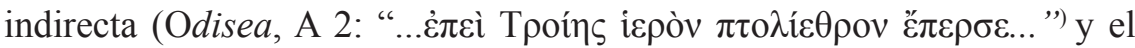
de valiente, atrevido y fuerte por la intervención divina. Asimismo, como adjetivo sustantivado aparece siempre con un significado vinculado a lo

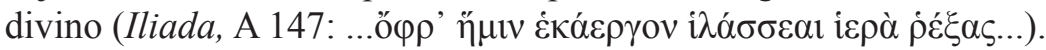

\section{Periodo arcaico}

En el periodo siguiente, el arcaico, aparte de las formas adjetival y sustantivada que continúan siendo empleadas con los significados anteriormente referidos, destaca, por primera vez, la sustantivación del término para caracterizar un lugar exento de toda "contaminación" terrenal que, con su cualidad de "sagrado", ofrece protección a los mortales, en referencia al lugar sagrado, al santuario, dedicado a Hera. Concretamente, con esta forma sustantivada significando el santuario, cuya evolución semántica desempeña un papel primordial en la historia de la religiosidad griega, inicia su andadura en el s. VIII a. C., en un texto de Eumelo recopilado en Corinthiaca fragmenta ${ }^{1}\left(3 \beta, 451, \Phi .2^{\alpha} .9^{2}\right.$ “ ....

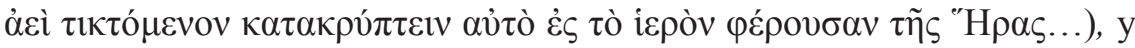
conservado por Pausanias. En la realidad pagana, y en primer lugar en el periodo arcaico, el i $\varepsilon \rho o ̀ v$ es el santuario dedicado a una de las divinidades del panteón olímpico o a divinidades inferiores que en varios casos son, tras su divinización, conceptos abstractos; es el lugar sagrado en el que el acceso estaba prohibido a todos, excepto a los sacerdotes ${ }^{3}$, como aparece en

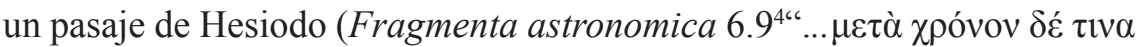

1 Vid.Amato, E., "Su due improbabibli citazioni dai Korinthiaká di Eumelo: un nuovo frammento lirico di autore incerto (Eschilo?) e un oracolo sibillino", Emerita, vol. 70, nº 1, 2002, pp. 45-68.

2 Bernabé, A. (ed.), Poetarum epicorum Graecorum testimonia et fragmenta, Leipzig, Ed. Teubner, 1987.

4 Diles, H.-Kranz, W. (eds.), Die Fragmente der Vorsokratiker, Dublín/ 


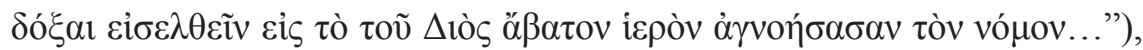
que se refiere a la constelación de la Osa y su procedencia ${ }^{5}$, y hace mención

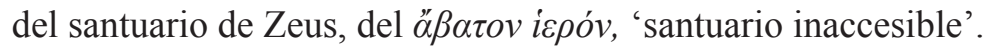

Además de aludir al santuario, la forma adjetival del término mantiene el concepto de sagrado como queda evidenciado con claridad en la obra de

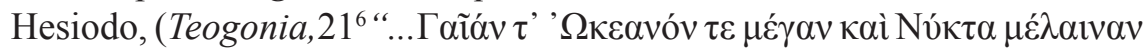

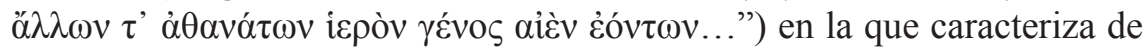
sagrado a la estirpe de las divinidades generadoras de vida refiriéndose a Gea, Océano, Noche y a los demás dioses inmortales. Píndaro, por su parte, en el Himno de Tebas a Zeus ${ }^{7}$ califica de sagrada a la estirpe de los hombres relacionados con Tebas ( “...'I

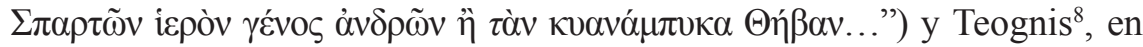

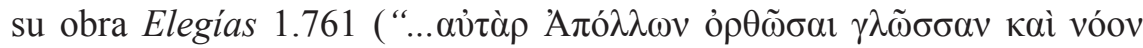

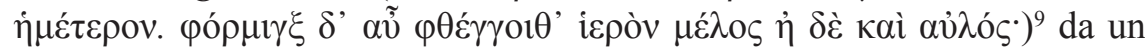
paso más y hace referencia con el término a la melodía sagrada de Apolo.

\section{Periodo clásico}

El uso del vocablo, como adjetivo y adjetivo sustantivado, continúa estando presente en la época clásica indicando, cuando va sustantivado, tanto las antiguas como las nuevas formas evolucionadas del lugar del culto. Los lugares sagrados, una cueva, una montaña o más tarde un recinto con o sin templo de madera, cedieron su lugar a la forma más evolucionada, a un recinto sagrado con templo de orden dórico o jónico y con todas las demás construcciones dedicadas a los dioses, en el caso de que existieran. Hay que reseñar que, en muchas ocasiones, es este mismo

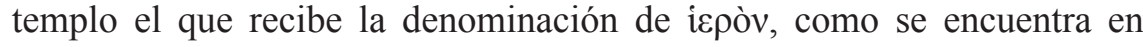

Zurich, 1966.

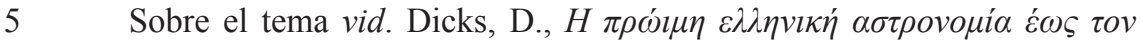

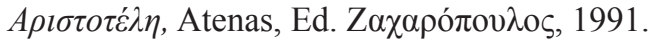

6 West, M.L. (ed.), Hesiodi Theogony, Oxford, Clarendon Press, 1966.

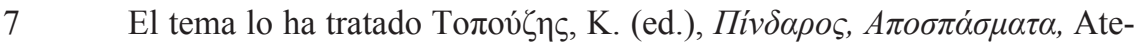

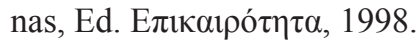

8 Referencias se encuentran en.X $\alpha \tau \zeta o \pi$ ov́ $\lambda$ ov, A. (ed.), "A $\pi \alpha v \tau \alpha$ :

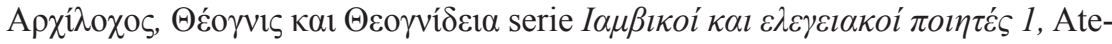

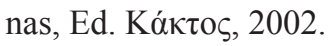




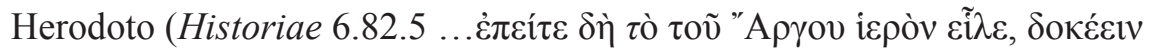

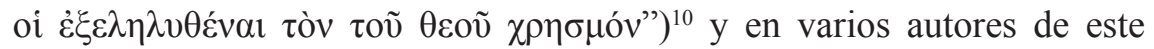
periodo. Sin embargo, durante toda la época clásica, la forma adjetival del término se utiliza en los casos en que, por la intervención de la divinidad, se adquiere santidad y en los que la presencia de la divinidad es continua y muestras, entre múltiples otras, se hallan en Sófocles (Fragmenta 535.1,

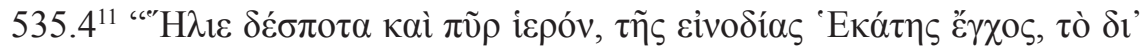

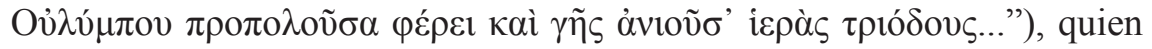

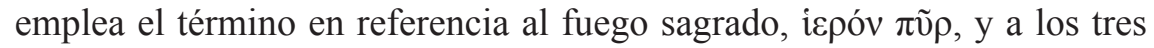

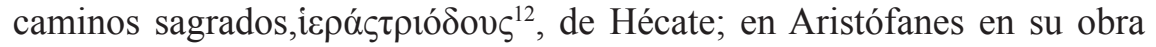

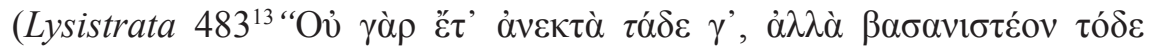

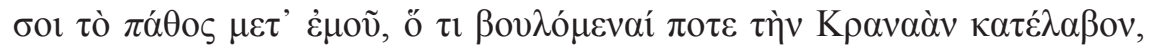

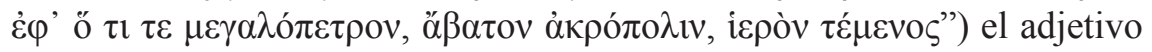

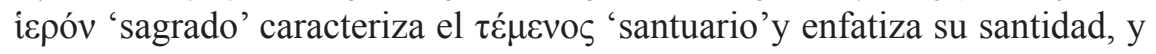

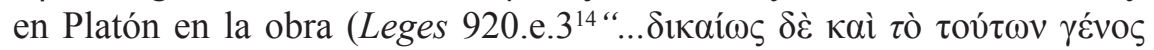

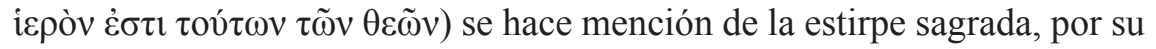
procedencia divina, de los creadores de las leyes.

\section{Periodo helenístico}

Llegando al periodo helenístico, periodo de transmisión en la historia

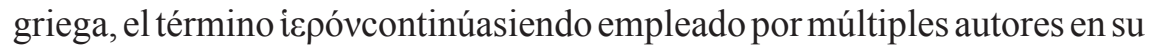
forma sustantivada con el mismo significado de santuario y templo y, como adjetivo para indicar, en diversos casos, la santidad por la presencia divina aunque ésta sea indirecta. El vocablo sustantivado lo emplea Calístenes para hacer referencia al primer santuario dedicado a Némesis llamado Adrastio por el nombre de su fundador, el rey Adrasto y se encuentra en un pasaje de Geográficos de Estrabón, quien utiliza a Calístenes como fuente

10 Legrand, Ph.-E. (ed.), Hérodote. Histories, París, Ed. Les Belles Lettres, 1948.

11 Radt, S. (ed.), Tragicorum Graecorum fragmenta, Gotingen, Ed. Vandenhoeck y Ruprecht, 1977.

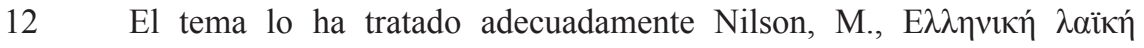

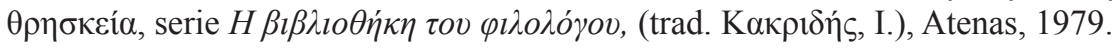

13 Coulon, V.-Van Daele, M. (eds.), Aristophane, vol. 3, 1967.

14 Ibídem, vol. 5, 1967. 


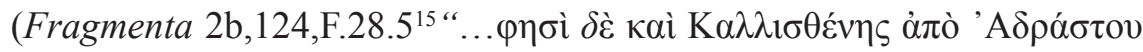

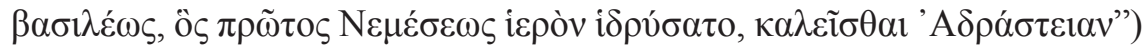
y Cleantesen un pasaje de los Míticos ${ }^{16}$, utilizado por Ateneo como fuente,

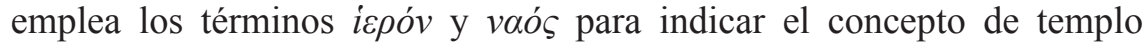
haciendo referencia al templo de Afrodita Prostituta ubicado en el pueblo de Pánfilo de la isla de Lesbos, como recordatorio de la salvación de los habitantes por una prostituta al ser ella quien abrió las puertas y permitió la salida a los conquistados (Testimonia et fragmenta 545.1 Athenaeus XIII

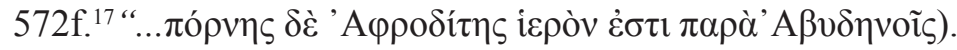

Una aproximación filosófica del término la encontramos en varios autoresen Epifanio o en Orígenes, transmitida al filósofo Zenón que niega la cualidad de lo "sagrado" y considera que el hombre no ha de construir y dedicar santuarios y templos a los dioses (Testimonia et fragmenta $265.3^{18}$

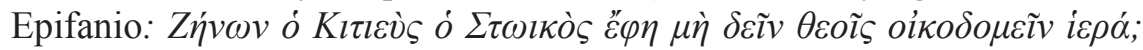

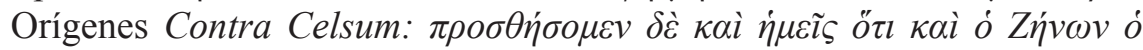

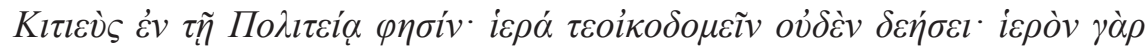

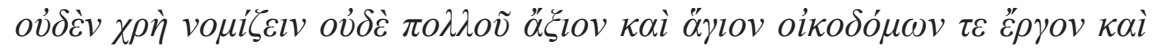
$\beta \alpha v \alpha v ́ \sigma \omega v)$.

Posteriormente se encuentra un ingente número de autores que

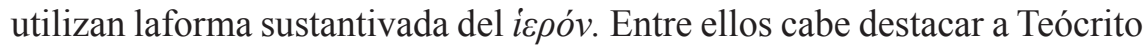
que hace referencia al santuario casto de Apolo (Idyllia 25.2219“...ö $\theta_{1}$

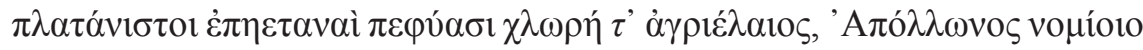

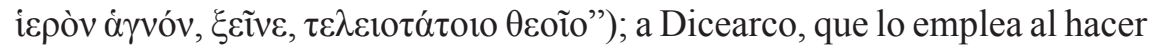
mención de Pitágoras y a su decisión de recurrir al santuario de las Musas en Metapontio para morir de inanición guardando ayuno durante cuarenta días, pasaje recopilado y conservado ${ }^{20}$ por Porfirioen la obra Vida de

15 Mette, H. J. (ed.), Die kleinen griechischen..., op. cit.

16 Referencias se encuentran en Gulick, C. B., (ed.), Athenaeus, The Deipnosophists. Cambridge, Ed. Harvard University Press, 1927-41.

17 Von Arnim, J. (ed.), Stoicorum veterum..., op. cit., vol. 1, Stugart, Ed. Teubner, 1968.

18 Von Arnim, J. (ed.), Stoicorum veterum fragmenta, vol.1, Stuttgart, Ed. Teubner, 1968.

19 Gow, A.S.F. (ed.), Theocritus, Cambridge, Ed. Cambridge University Press, 1965.

Vid. Nauck, A. (ed.), Vita Pythagorae en Porphyrii philosophi Platonici 


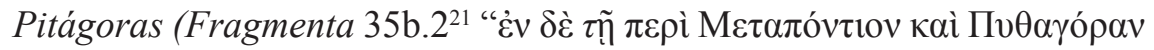

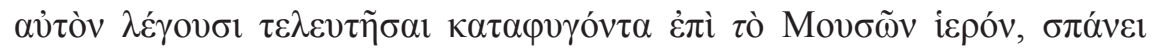

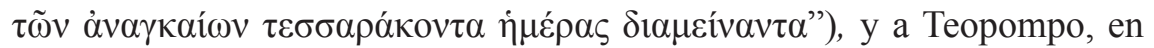
un pasaje recopilado y conservado ${ }^{22}$ por Ateneo en su obra Banquete de los sofistas, que se refiere al santuario de Apolo en Delfos (Fragmenta

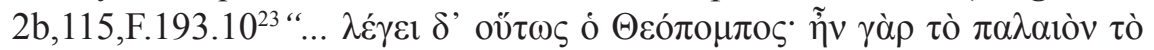

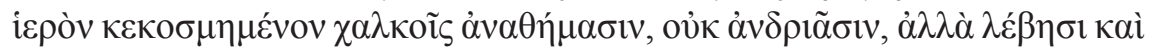

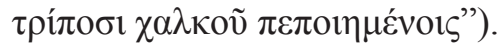

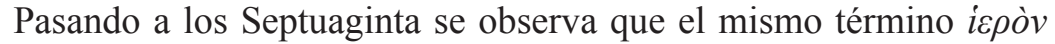
está empleado para indicar el templo monoteísta de Jerusalén (Esdras

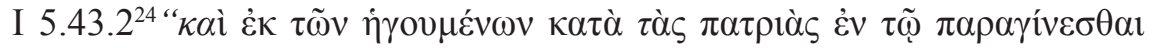

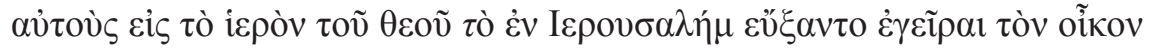

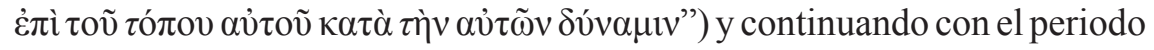

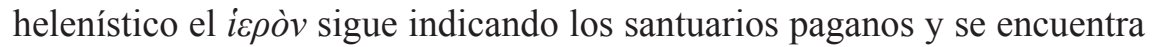
con esta misma acepción en varios autores, como Polibio, Apolodoro de Atenas, Apolonio, Dionisio Escitobraquión, Zenón de Rodas, Posidonio de Apamea y Asclepiades, mientras que en Bión de Esmirna ${ }^{25}$ el ícpòv se utiliza metafóricamente para caracterizar la estrella Héspero como templo

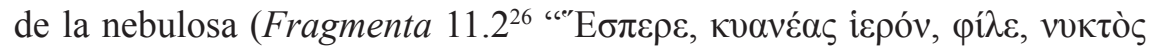

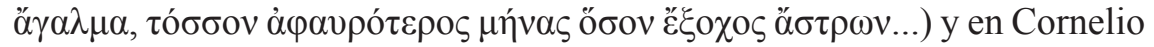
Alejandro se menciona la profecía de Elías que ya estaba reproducida en el fragmento de Eupólemo sobre David y Salomón. Según ésta, David construiría en Jerusalén el templo dedicado al Dios único y verdadero

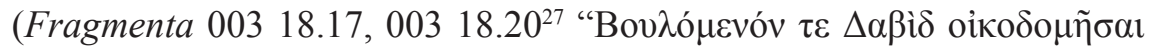

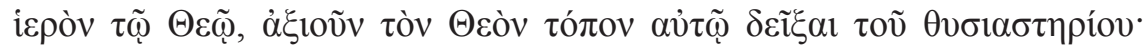

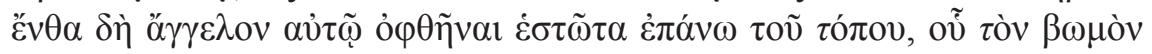

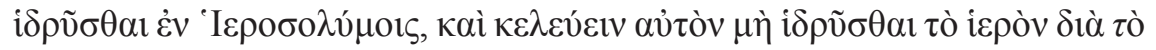

opuscula, Hildesheim, Ed. Olms, 1963, pp. 17-52.

21 Wehrli, F. (ed.), Dikaiarchos, Basel, Ed. Schwabe, 1967.

22 Vid.Kaibel, G. (ed.), “Deipnosophistae...”, op. cit.

23 Mette, H.J. (ed.), Die kleinen griechischen..., op. cit..

24 Rahlfs, A. (ed.), Septuaginta, vol. 1, op. cit.

25 Vid. Gow, A.S.F. (ed.), "Fragmenta enBucoli...”, op. cit.

26 Gow, A.S.F. (ed.), Bucoli Graeci, Oxford, Ed. Clarendon Press, 1969.

27 Ibídem. 


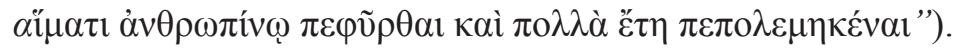

Una mención interesante se encuentra en la obra Sobre la diferencia de las palabras de Ptolomeo, donde se presenta la diferencia entre ö $\sigma ı \mathrm{v}$

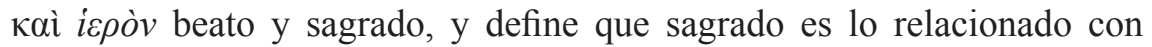
los dioses cuya aproximación es imposible al contrario de lo beato que se relaciona con la privacidad y la posible proximidad (De differentia

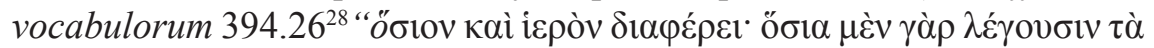

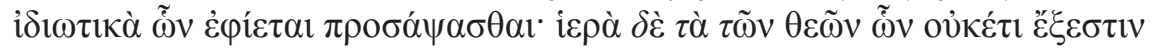
$\pi \rho о \sigma \alpha ́ \psi \alpha \sigma \theta \alpha \imath ")$.

\section{Periodo romano}

En la época romana, la protocristiana, cuando la realidad religiosa va cambiando, y aparte del paganismo y del judaísmo, el Cristianismo se va extendiendo, hay que mencionar que dicha realidad reflejada en el campo lingüístico llama la atención, porque se observa que, para expresar los nuevos conceptos y las exigencias del culto, se emplearon términos existentes en el léxico religioso pagano.

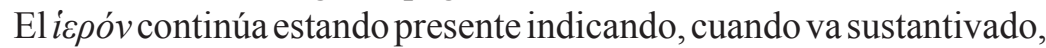
tanto los santuarios y templos paganos como el templo dedicado al Dios del monoteísmo y, principalmente, el templo de Jerusalén, y cuando se emplea con uso adjetival con el significado más generalizado de sagrado referido a lugares y a seres vivos, tanto a hombres como animales, y a algunas acepciones abstractas.

Así, múltiples autores emplean el término para hacer referencia a santuarios paganos y entre otros se encuentran: Diodoro Sículo, quien en su obra Bibliotheca historica menciona el santuario que se hallaba en Tebas de Egipto dedicado a Zeus y a Hera; Dionisio de Halicarnaso que en Antiquitates Romanae ${ }^{29}$ alude al santuario de Afrodita Eniada en

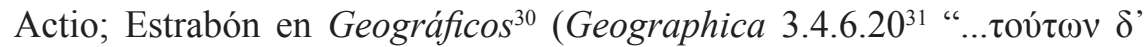

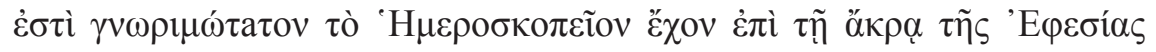

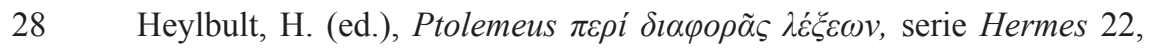
1887.

29 Vid. Jakoby, K. (ed.), “Antiquitates Romanae...”, op. cit.

30 Vid. Meineke, A. (ed.), “Geographica...”, op. cit.

31 Meineke, A. (ed.), Estrabónis geographica, vol. 1, Graz, Ed. Akademische Druck- und Verlagsanstalt, 1969. 


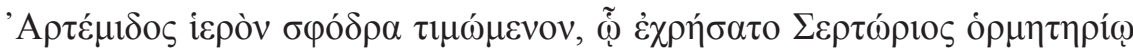
$\left.\kappa \alpha \tau \grave{\alpha} \theta \dot{\alpha} \lambda \alpha \tau \tau \alpha v^{\prime \prime}\right)$ describe el santuario de Artemisa de Éfeso ubicado en Hemeroskopeion, colonia griega cerca de Marsella; Ateneo ${ }^{32}$ menciona con este vocablo la parte mecánica del templo de Éfeso, mientras que en un fragmento de Atenodoro de Tarso hallado en Clemente de Alejandría se alude al santuario de Sérapis; Domicio Calístrato en su descripción Sobre Samotracia, cuya referencia se encuentra en Dionisio de Halicarnaso ${ }^{33}$, se sirve del término para referirse al santuario de los Grandes Dioses hallado en la isla de Samotracia.

En Filón de Alejandría encontramos, además, una dimensión filosófica sobre los lugares sagrados. Este autor, en su obra De specialibus legibus, se refiere con este vocablo a un Dios único y a su relación con los lugares sagrados, los santuarios, los templos y niega la necesidad de la existencia de dichos edificios (De specialibus legibus 1.66.t1 - 1.66.5

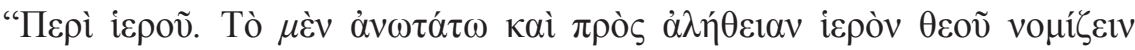

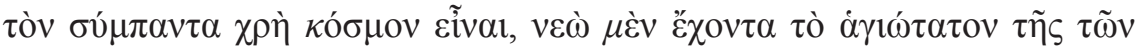

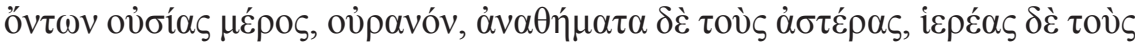

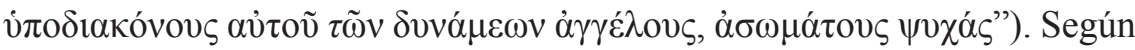
él, para Dios el santuario es el mismo universo, el cielo es su templo, las ofrendas son las estrellas y los sacerdotes son sus subdiáconos, los ángeles, las almas inmateriales. Sin embargo, el mismo Filón en sus obras utiliza el término para indicar el templo, el edificio, dedicado al Dios del monoteísmo.

Siguiendo el recorrido durante el periodo romano y los primeros años después de Cristo, y concretamente en el s. I d. C. el autor judío y gran defensor de la religión judaica Flavio Josefo escribe en griego su

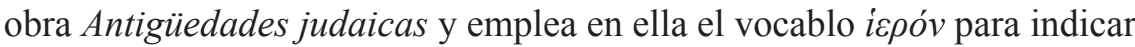
el templo judío en el que, como ya se ha mencionado durante el Imperio Romano, se observaba una mezcla de religiones y cultos, y entre ellos el judaísmo ${ }^{35}$.

32 Vid. Schneider, R. (ed.), “De machinas...”, op. cit.

33 Vid. Jakoby, K. (ed.), “Antiquitates Romanae enDionysii Halicarnasei...", op. cit. 1.68.3.8.

34 Cohn, L. (ed.), Philonis Alexandrini opera quae supersunt, vol. 5, Berlín, Ed. De Gruyter, 1962.

35 Referencias sobre el tema se encuentran en "Flavio Josefo" en Enciclo- 
La comprobación del uso del mismo término para indicar diferentes expresiones del culto continúa en el Nuevo Testamento. El ícò̀v aparece con su forma sustantivada indicando, por un lado, los templos paganos

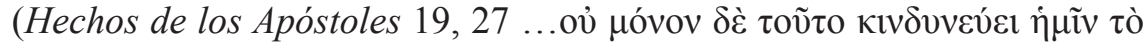

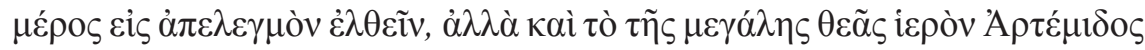

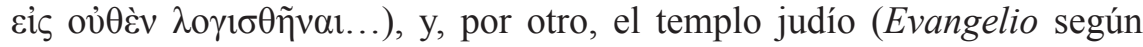

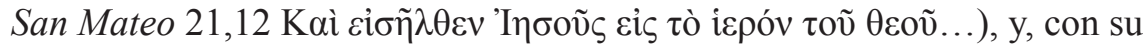
forma adjetival para indicar, en diversos casos, la santidad.

En el s. II d. C. el término se encuentra en forma sustantivada y adjetival en el primer erudito cristiano, Clemente de Alejandría quien intentó armonizar la filosofía griega con la filosofía del Cristianismo y convencer a los griegos de que se convirtieran en cristianos y a los cristianos de que se educaran y aceptaran la herencia cultural nacional. Él utiliza

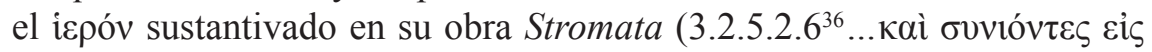

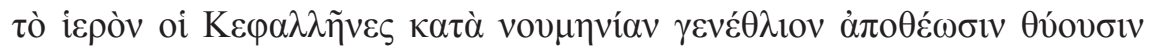

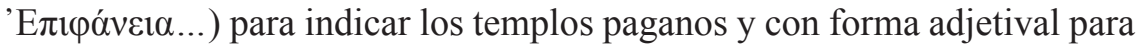
caracterizar como sagrados lugares o situaciones con presencia divina

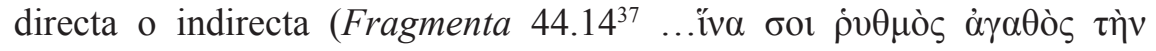

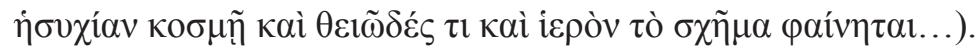

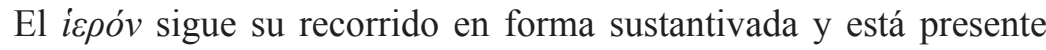
durante los siguientes siglos del periodo romano indicando, por un lado, los santuarios y los templos paganos y, por otro, el templo judío de Jerusalén. Se encuentra en múltiples autores y entre ellos deben ser citados Dión Casio en sus Historias Romanas, Flavio Filóstrato en su obra Vida de Apolo, Ateneo en Banquete de los sofistas, Diógenes Laercio en Colección de vidas y opiniones de filósifos, Heliodoro de Émesa en Etiópicas, Eutecnio en Paraphrasis in Nicandri alexipharmaca, Hipólito

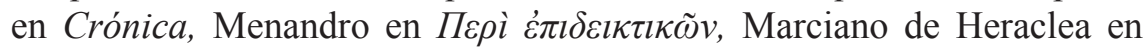

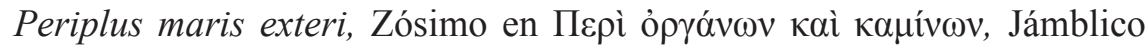
en De vita Pythagorica, Eusebio en Praeparatio evangelica, Trifiodoro en

pedia Judaica 10, Jerusalén, 1971, col. 257; Cohen, S.J.D., Josefo en Galilea y Roma, Leiden, 1979.

36 Stählin, O.-Früchtel, L.-Treu, U. (eds.), Clemens Alexandrinus, vol. 3, Berlín, Ed. Akademie-Verlag, 1970.

37 Stählin, O.-Früchtel, L.-Treu, U. (eds.), Clemens Alexandrinus, op. cit., vol. 3. 
Toma de Troya y por último, el gran enemigo de Cristianismo, Porfirio ${ }^{38}$, en Quaestionum Homericarum ad Iliadem pertinentium reliquiae, mientras que Orígenes en Commentarium in evangelium Matthaei emplea el término para indicar el templo de Jerusalén.

Asimismo, continúa estando presente como adjetivo en multitud de obras en las que el significado más generalizado es el de sagrado referido a lugares, como se manifiesta en las obras Bibliotheca historicade Diodoro Sículo, Antiquitates Romanae de Dionisio de Halicarnaso, Geográficos

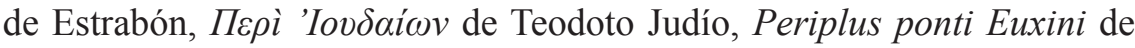
Flavio Arriano, Graeciae Descriptio de Pausanias Periegeta, Graeciae Descriptio de Dionisio, Geographia de Claudio Ptolomeo, Strategemata de Polieno, Historiae Romanae de Dión Casio, en el Testamento de Salomón Narratio de propheta et sapientissimo rege Salomone (cod. Monasterii sancti Saba 290), Sobre la gruta de las ninfas de Porfirio y en Toma de Troya de Trifiodoro.

Igualmente, con forma adjetival se emplea con profusión para indicar la santidad procedente de la presencia divina indirecta en los seres, tanto en los hombres como en los animales, y en algunas acepciones abstractas. Sagrado es la caracterización de aquellas personas que se distinguen por sus cualidades indiscutibles. En este sentido Luciano, en su obra El aficionado a la mentira o el incrédulo, define como sagrado al maestro inteligente, a Pangrates. Diógenes Laercio, en Colección de vidas y opiniones de filósofos, ofrece datos sobre la vida y la obra del filósofo y poeta Crantor y presenta la característica, otorgada por el poeta Teeteto, de sagrado.

El primer autor cristiano, Clemente de Alejandría, por su parte, señala la forma modesta y prudente de estar y comportarse para que la presencia del hombre se acerque a lo divino y lo sagrado (Fragmenta 44.1439 "iv $\mathrm{iv} \alpha$

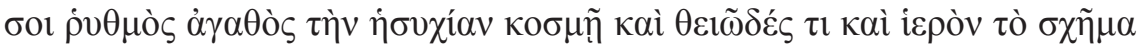

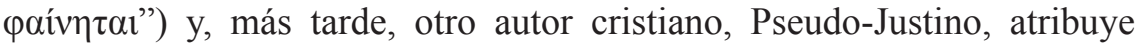
santidad, al prudente y carismático Clemente de Alejandría (Fragmenta

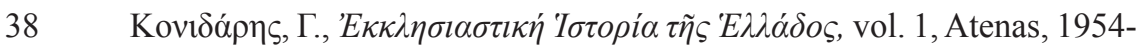
1960, p. 417.

39 Stählin, O.-Früchtel, L.-Treu, U. (eds.), Clemens Alexandrinus, op. cit., vol. 3 . 


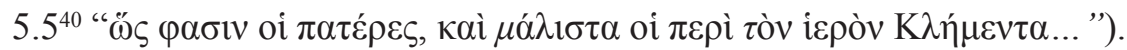

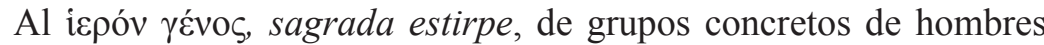
a los que se les ha conferido santidad hacen referencia Julio Pólux y Heliodoro. El primero caracteriza como sagrada la casta sacerdotal de

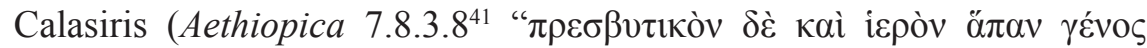

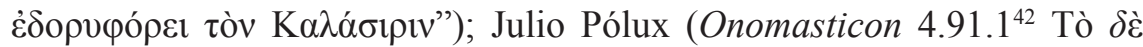

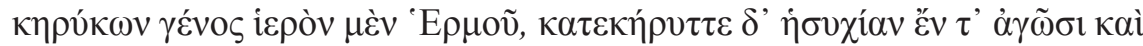

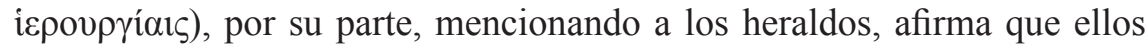
pertenecen a la estirpe sagrada de Hermes porque son los encargados de las responsabilidades protegidas por este mismo dios, responsabilidades que son, asimismo, asumidas por la divinidad, léase las del anuncio, del aviso y de la información.

A la santidad del consejo hace mención en el siglo II d. C. Zenobio analizando en Epitome collectionum Lucilli Tarrhaei et Didymi el refrán que cita Epicarmo y aclara que en casos difíciles el consejo dado con mente despejada es conveniente también Jámblico, en su obra De vita Pythagorica, asegura que el consejo es sagrado.

Además, el Evangelio de San Marcos en el Nuevo Testamento atribuye santidad a la predicación de Jesucristo que a través de los apóstoles

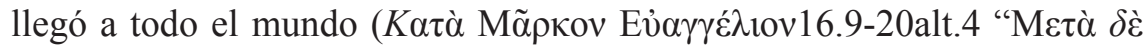

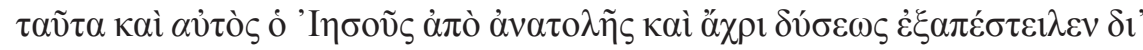

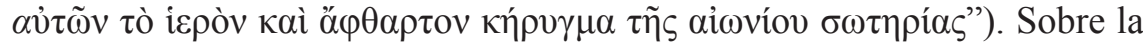
palabra sagrada hacen referencia Galeno en su obra De usu partium, Flavio Filóstrato en Vita Apollonii en la que menciona la visita de Apolonio y de sus acompañantes a Egipto donde enseñaron y aprendieron las palabras sagradas.

Otra dimensión de la que disfruta el término es la de caracterizar animales o aves como sagrados. De esta manera en la obra de Lucio Anneo Cornuto De natura deorum ${ }^{43}$ aparece el ave de rapiña por ser ésta el ave

40 Otto, J.C.T. (ed.), Corpus apologetarum Christianorum saeculi secundi, vol. 5, Wiesbaden, Ed. Sändig, 1969.

41 Rattenbury, R.M.-Lumb, T.W.-Maillon, J. (eds.), Héliodore. Les Ethiopiques (Théagène et Chariclée), París, Ed. Les Belles Lettres, 1960.

42 Bethe, E. (ed.), Pollucis onomasticon, serie Lexicographi Graeci, Stuttgart, Ed. Teubner, 1967.

43 Lang, C. (ed.), Cornuti theologiae Graecae compendium, Leipzig, Ed. 


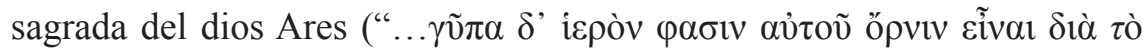

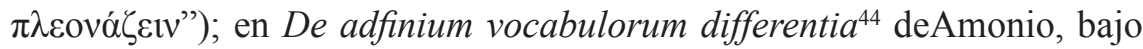

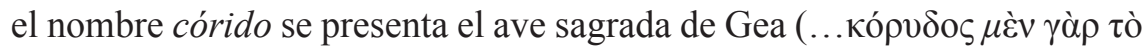

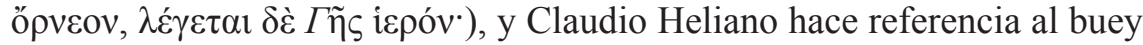
de cinco patas dedicado a Zeus en De natura animalium $11.40 .17^{45}$ " $\dot{\varepsilon} \gamma \omega \grave{\delta} \delta \grave{\varepsilon}$

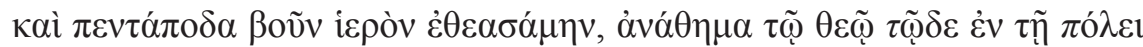
$\left.\tau \tilde{n}{ }^{\prime} A \lambda \varepsilon \xi \alpha \nu \delta \rho \varepsilon ́ \omega \nu \tau \tilde{n} \mu \varepsilon \gamma \alpha \dot{\alpha} \lambda \eta^{\prime \prime}\right)$.

Igualmente, santidad adquieren algunas plantas como aparece en Orationes de Dión Crisóstomo al referir el caso del fruto del olivo que es sagrado por ser el árbol de Atenea; en el Timoleón de Plutarco se menciona el apio como planta sagrada con la que se hacen las coronas para los ganadores de los juegos del Istmo de Corinto.

Trifón, por su parte, señala como sagrado el enfado de Alcinoo, y Filón de Alejandría confiere santidad al fuego del éter no sofocado y lo caracteriza į́óv $\pi \tilde{v} \rho$, fuego sagrado, y esta misma característica un siglo más tarde la manifiestan Diogeniano de Heraclea en su obra Paroemiae y

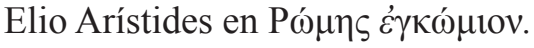

Una dimensión diferente le infiere Dioscórides Pedanio en Materia médica donde presenta los nombres de varias materias medicinales que, en algunos casos, pueden ser plantas y entre ellas hay una que recibe la denominación de į́óv.

\section{Conclusiones}

Concluyendo, se observa que el término, desde su primera presencia en Homero como adjetivo y más tarde en Eumelo como adjetivo sustantivado, sigue un trayecto incesante hasta la época romana e incluso hasta la actualidad. La Iliada y la Odisea de Homero son las obras en las que el término ípóv se encuentra con forma de adjetivo por primera vez en la literatura griega con el significado de valiente, atrevido, fuerte y de grande, y con el de sagrado para caracterizar lugares, objetos, personas o situaciones anímicas y, en general, casos abstractos y concretos a quienes

Teubner, 1881.

44 Nickau, K. (ed.), Ammonii qui dicitur liberde adfinium vocabulorum differentia, Leipzig, Ed. Teubner, 1966.

45 Hercher, R. (ed.), Aeliani de natura animalium libri xvii, varia historia, epistolae, fragmenta, vol. 1, Graz, Ed. Akademische Druck und Verlagsanstalt, 1971. 
se les confiere santidad, por la presencia divina indirecta.

En el periodo arcaico, aparte de la forma adjetival que continúa siendo empleada, destaca la sustantivación del término, cuya evolución semántica desempeña un papel primordial en la historia de la religiosidad griega.

Con su forma sustantivada desde el inicio de su andadura, en Eumelo, declara el lugar sagrado dedicado a la divinidad. En la realidad pagana, y en primer lugar en el periodo arcaico, es el santuario dedicado a una de las divinidades del panteón olímpico o a divinidades inferiores que, en varios casos, son tras su divinización, conceptos abstractos.

El uso del vocablo, como adjetivo y adjetivo sustantivado, continúa estando presente en la época clásica indicando, cuando va sustantivado, tanto las antiguas como las nuevas formas evolucionadas del lugar del culto. Los lugares sagrados, una cueva, una montaña o más tarde un recinto con o sin templo de madera, cedieron su lugar a la forma más evolucionada, a un recinto sagrado con templo de orden dórico o jónico y con todas las demás construcciones dedicadas a los dioses, en el caso de que existieran. Hay que reseñar que, en muchas ocasiones, es este mismo templo el que recibe la denominación de ípòv. Sin embargo, durante toda la época clásica, la forma adjetival del término se utiliza en los casos en que, por la intervención de la divinidad, se adquiere santidad y en los que la presencia de la divinidad es continua.

Llegando al periodo helenístico, periodo de transmisión en la historia griega, el uso del término ífóv continúa siendo empleado, con su forma sustantivada y con el mismo significado de santuario y de templo, indicando los santuarios y los templos paganos, pero también el templo monoteísta de Jerusalén. Sin embargo, no carece de la forma adjetival para indicar, en diversos casos, la santidad por la presencia divina aunque ésta sea indirecta.

En la época romana, la protocristiana, cuando la realidad religiosa va cambiando, y aparte del paganismo y del judaísmo, el Cristianismo se va extendiendo, hay que mencionar que dicha realidad reflejada en el campo lingüístico llama la atención, porque se observa que, para expresar los nuevos conceptos y las exigencias del culto, se emplearon términos existentes en el léxico religioso pagano. Así en el Nuevo Testamento se atribuye santidad a la predicación de Jesucristo como anteriormente se hizo utilizando el término citado con las palabras de las tragedias antiguas. 


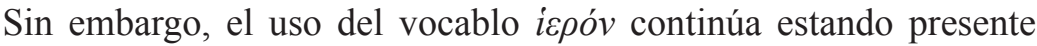
indicando, cuando va sustantivado, tanto los santuarios y templos paganos como el templo dedicado al Dios del monoteísmo y principalmente el templo de Jerusalén, y cuando se emplea con uso adjetival con el significado más generalizado de sagrado referido a lugares y a seres vivos, tanto a hombres como animales, y a algunas acepciones abstractas por la santidad procedente de la presencia divina indirecta.

\section{REFERENCIAS BIBLIOGRÁFICAS}

AMATO, E. (2002). "Su due improbabibli citazioni dai Korinthiaká di Eumelo: un nuovo frammento lirico di autore incerto (Eschilo?) en un oracolo sibillino", Emerita, vol. 70, n' 1, 45-68.

BERNABÉ, A. (1987). Poetarum epicorum Graecorum testimonia et fragmenta, Leipzig: Ed. Teubner.

BETHE, E. (ed.), Pollucis onomasticon, serie Lexicographi Graeci, Stuttgart, Ed. Teubner, 1967.

BURKERT, W. (2007). Religión griega arcaica y clásica, (transl. Bernabé, H.), Madrid.

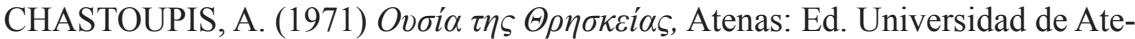
nas.

COHEN, S.J.D. (1979). Josefo en Galilea y Roma, Leiden,

COHN, L. (ed.), (1962). Philonis Alexandrini opera quae supersunt, vol. 5, Berlín: Ed. De Gruyter,

COOPER, J. (2006) Panentheism: The Other God of the Philosophers - From Plato to the Present, Michigan: Baker Academic.

COULON, V.-VAN DAELE, M. (eds.), (1967). Aristophane vol. 3 y 5, París: Ed. Les Belles Lettres.

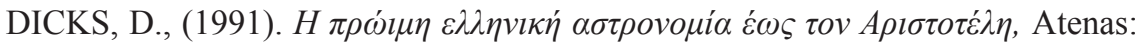

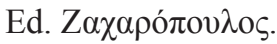

DILES, H.-KRANZ, W. (eds.), (1966). Die Fragmente der Vorsokratiker, Dublín/ Zurich,

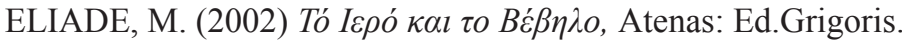

GOW, A.S.F. (ed.), (1965). Theocritus, Cambridge: Ed. Cambridge University Press.

GOW, A.S.F. (ed.), (1969). Bucoli Graeci, Oxford: Ed. Clarendon Press.

GULICK, C. B., (ed.), (1927-41). Athenaeus, The Deipnosophists, Cambridge: Ed. Harvard University Press.

HERCHER, R. (ed.), (1866). Claudii Aeliani de natura animalium libri xvii, varia historia, epistolae, fragmenta, Vol. 2, Leipzig: Teubner.

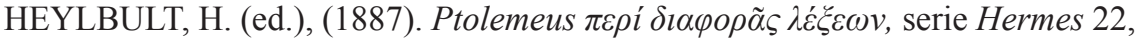


JAKOBY, K. (ed.), 1967. Antiquitates Romanae en Dionysii Halicarnasei antiquitatum Romanum quae supersunt, vol. 1, Stuttgart: Ed. Teubner.

KAIBEL, G. (ed.), (1965). "Deipnosophistae" en Athenaei Naucratitae deipnosophistarum, Stuttgart: Ed. Teubner.

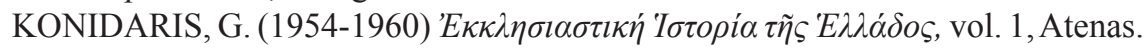

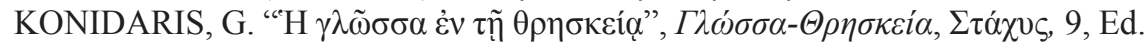

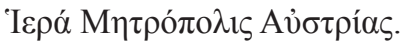

LANG, C. (ed.), Cornuti theologiae Graecae compendium, Leipzig, Ed. Teubner, 1881.

LEGRAND, PH. (ed.), (1948). Hérodote. Histories, París : Ed. Les Belles Lettres.

MEINEKE, A. (ed.), (1969). Estrabónis geographica, vol. 1, Graz, Ed. Akademische Druck- und Verlagsanstalt.

METTE, H. J. (ed.), (1978). Testimonia en Die kleinen griechischen Historiker heute, serie Lustrum 21.

METTE, H.J. (ed.), (1978). "Die kleinen griechischen Historiker heute" Lustrum 21, 5-43.

NAUCK, A. (ed.), (1963). Vita Pythagorae en Porphyrii philosophi Platonici opuscula, Hildesheim: Ed. Olms.

NICKAU, K. (ed.), Ammonii qui dicitur liberde adfinium vocabulorum differentia, Leipzig, Ed. Teubner, 1966.

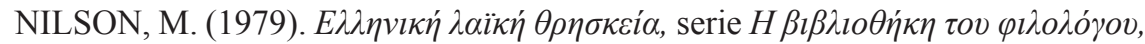

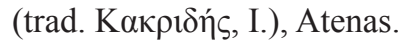

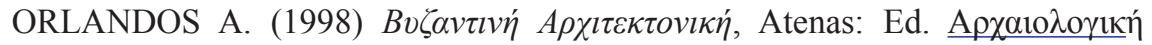

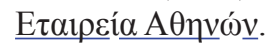

OTTO, J.C.T. (ed.), Corpus apologetarum Christianorum saeculi secundi, vol. 5, Wiesbaden, Ed. Sändig, 1969.

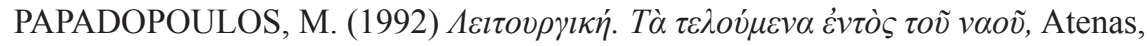
Ed. Eptalofos A.B.E.E.

RADT, S. (ed.), (1977). Tragicorum Graecorum fragmenta, Gotingen: Ed. Vandenhoeck y Ruprecht

RATTENBURY, R.M.-LUMB, T.W.-MAILLON, J. (eds.), Héliodore. Les Ethiopiques (Théagène et Chariclée), París, Ed. Les Belles Lettres, 1960.

SCHNEIDER, R. (ed.), (1912). De machinas en Griechische Poliorketiker, vol.1, Berlín: Ed. Weidmann.

SEPTUAGINTA:http://www.hs-augsburg.de/ harsch/graeca/Chronologia/S_ ante03/VT/vte_pd00.html (19-02-2019).

STÄHLIN, O.-FRÜCHTEL, L.-TREU, U. (eds.), (1970). Clemens Alexandrinus, vol. 3, Berlín : Ed. Akademie-Verlag.

VON ARNIM, J. (ed.), (1968). Stoicorum veterum fragmenta, vol.1, Stuttgart: Ed. Teubner.

WEHRLI, F. (ed.), (1967). Dikaiarchos, Basel: Ed. Schwabe. 
WEST, M.L. (ed.), (1966). Hesiodi Theogony, Oxford, Clarendon Press.

YOUNG, D.-DIEHL, E. (eds.), (1971). Theognis, Leipzig: Ed. Teubner.

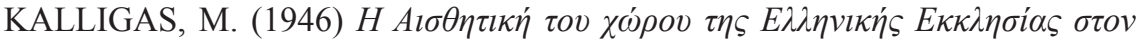

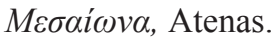

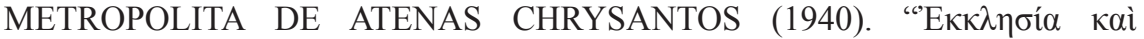

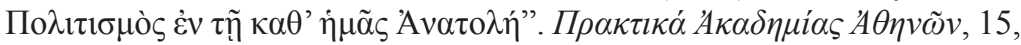
77.

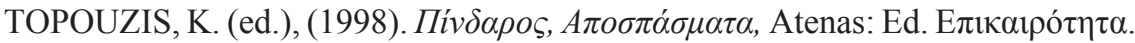

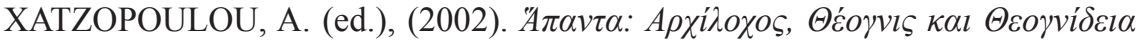

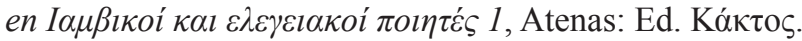

